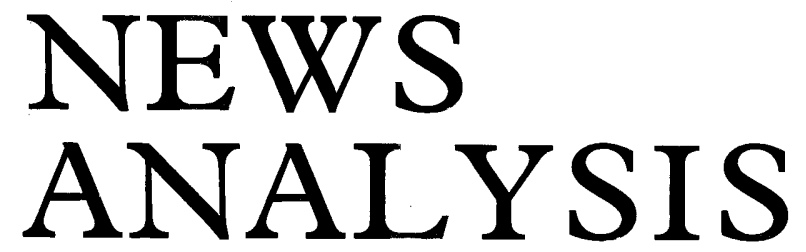

- Argentina te

A quiero

* In most countries the midday bombing of a foreign consulate, mass transit strikes, economic instability, and the tragic loss of the leader of the anti-smoking community might have led to the postponement or cancellation of a major meeting on tobacco. Not so Argentina, where on 30 March-3 April 1992 more than 1000 determined individuals from nearly 80 countries (including all Latin American nations) attended the eighth world conference on tobacco or health. Buenos Aires proved to be a tremendously hospitable city, and both the host committee and conference organisers at the American Cancer Society (ACS) succeeded in putting on a remarkable meeting. At the opening ceremonies, attended by Argentine President Carlos Saúl Menem and dignitaries from the World Health Organisation and UNICEF, the ACS' Allan Erickson paid a moving tribute to the late $\mathrm{Dr}$ Carlos Alvarez Herrera, whose outstanding efforts had laid the foundation for tobacco control in Argentina (see obituary in Tobacco Control 1992; 1: 60-1).

And from the moment one arrives, it is evident that much remains to be done. Forty four indoor billboards for Marlboro represent virtually the only advertising in the Buenos Aires airport, except for the signs in the duty free shops for Camel, John Player Special, Barclay, and other cigarette brands. Even the luggage carts advertise Marlboro, as well as the news stands and overhead clocks. Most of the billboards along the highways promote either Philip Morris's Marlboro or BAT's Jockey Club. In the city centre, virtually every news stand and snack shop has an overhanging sign advertising either Marlboro or Jockey Club. Along fences and construction sites - not to mention the front of the headquarters hotel - dozens upon dozens of posters for the Philip Morris brand of cigarettes line the avenues. Packages of ten cigarettes are inexpensive and popular. Magazine and newspaper

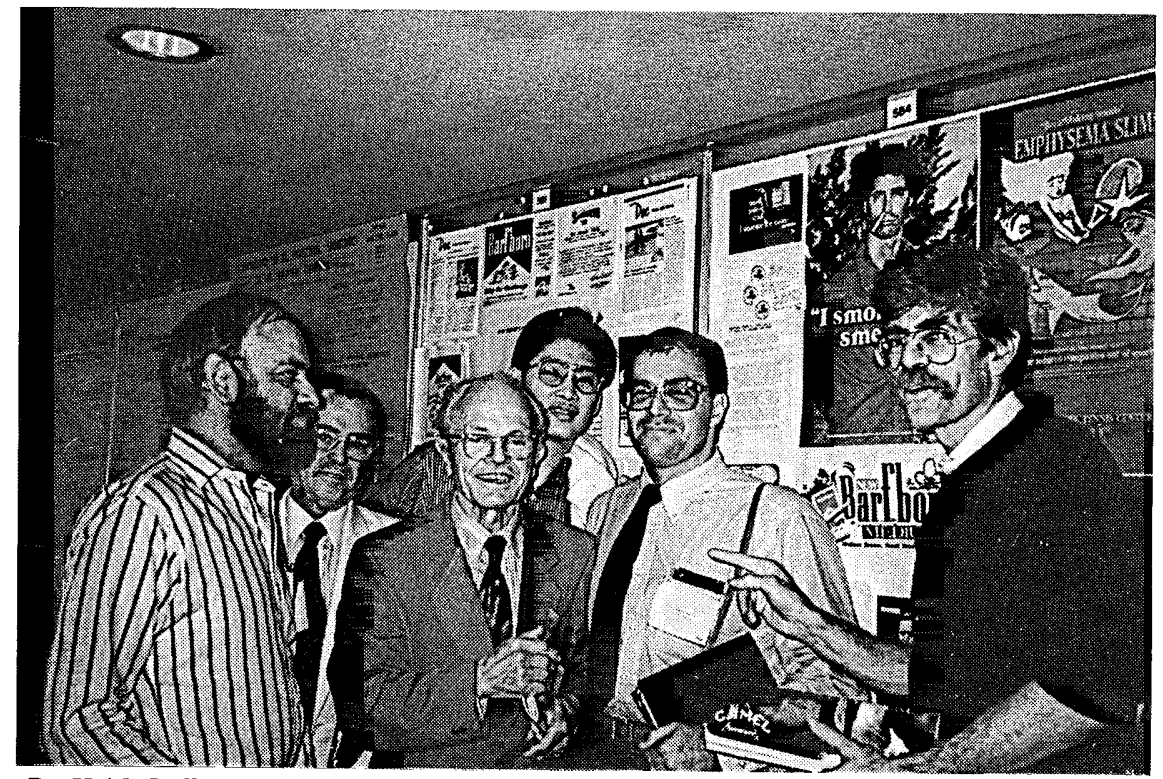

Dr Keith Ball (centre), a major contributor to tobacco control efforts in Africa, surrounded by well wishers from Africa, the Philippines, and the United States

advertising for cigarettes is minimal, although the motorcycle and car racing magazines contained the predictable collection of cigarette brand logos on vehicles and uniforms. A well timed editorial in the $31 \mathrm{March}$ issue of $E l$ Gráfico, the leading sports magazine, criticised tobacco company involvement in sports, but apart from a televised soccer match in which one of the teams wore Lucky Strike logos, I saw no tobacco advertisements on television.

Two jeans stores in prime locations featured large window displays for Marlboro Leisure Wear. Marlboro socks were $\$ 12$, shirts $\$ 50$, and jeans $\$ 48$. Belts, wallets, jackets, and sunglasses were also available. In the hotel gift shop, Tobacco Control editor Ron Davis purchased a toy Camel racing car (see figure), thus embarrassing Dr John Slade, heretofore the best at discovering the myriad guises of tobacco promotions.

Eight pre-conference meetings were held on Monday $30 \mathrm{March}$, involving special networks active against tobacco, including dentists, physicians, government representatives, Seventh Day Adventist Church members, and the International Network of Women Against Tobacco. A special briefing was held by US Sur- geon General Antonia Novello, the Pan American Health Organisation, and others responsible for producing the 1992 Surgeon General's report, Smoking and Health in the Americas (see p 150).

After the opening ceremony Monday evening, each of next three days focused on one of the following themes: countering tobacco marketing, advertising, and promotion; preventing tobacco use by children; and establishing clean indoor air policies. The final day was devoted to the topic of building support for tobacco control (see p 126), and included strategic planning sessions for each of seven regions of the world. Attendees were treated to a variety of plenary sessions; panel discussions, including one involving a dozen or so ministers of health; skill sharpening programmes; roundtable discussions; an entertaining dramatisation of a debate on clean indoor air policies; 400 scientific presentations; 100 poster presentations; and a dozen video presentations.

The most compelling presentations I attended included Dr Slade's explanation of the wholesale and retail distribution systems for cigarettes and other tobacco products in the United States; Dr Daniel Tan's exposé of the 


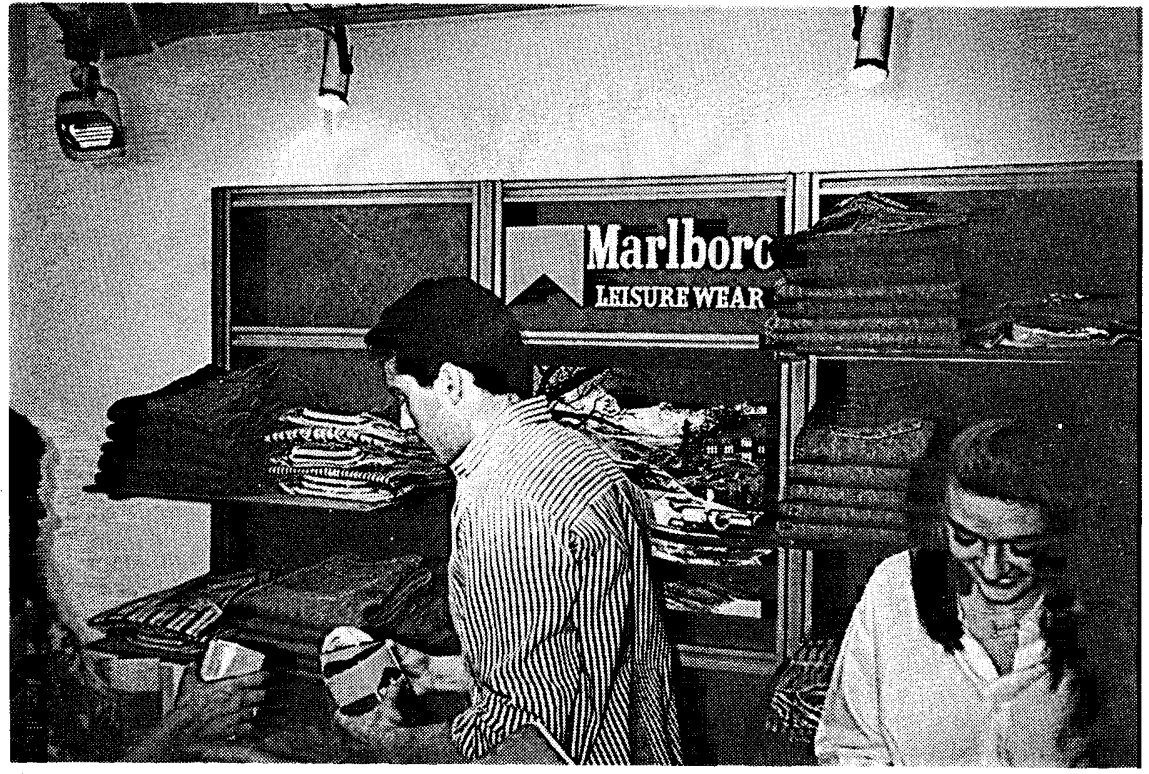

Cigarette brand clothing display in a Buenos Aires jeans store

tobacco industry's use of sports, cultural events, and politicians in the Philippines; Dr Judith Mackay's analysis of global tobacco economics; Lona Hegeman's observations of tobacco use among aboriginal teenagers in Saskatchewan; Dr Erma Lawson's touching commentary on low income pregnant adolescents in Kentucky who continue to smoke despite learning that smoking can lower birth weight; because smaller babies make easier deliveries; Dr Bob Robinson's description of efforts by African Americans to counteract tobacco promotions; Maria Villela's overview of smoking and Latin American women; and Vera Luiza da Costa e Silva's look at the history of women and tobacco advertising in Brazil.

A heartening trend is the growing number of papers on smoking and feminism (see $p$ 123). The conference served to launch a monograph, Women and Tobacco, by $\mathrm{Dr}$ Claire Chollat-Traquet and colleagues at the World Health Organisation, and the honorary chair of the conference was US Surgeon General Antonia Novello.

Undoubtedly one of the most heated debates followed the presentation by attorney Kathy Scheg of US Action on Smoking and Health (ASH) on her organisation's advocacy of filing child abuse complaints when parents or others smoke near children.

My most heartfelt moment at the conference was seeing Dr Ted Chen, executive director of the Asian Pacific Association for the Control of Tobacco (APACT) sitting alone, eyes closed, deep in thought, in a dark corner of a local restaurant. It came as a great disappointment that the ex- cellent progress of APACT was set back by international politics involving the People's Republic of China and Taiwan which had nothing to do

The expense of travelling to Buenos Aires prevented numerous outstanding individuals from attending the conference. It was a particular shame that after having hosted such an enlivening get together in Perth, Australia, in 1990, the Australian contingent was missing several of its star players, including Victoria Health Promotion Foundation creator $\mathrm{Dr}$ Nigel Gray and Non-Smokers Rights Association gurus Dr Arthur Chesterfield-Evans and Peter Markham. New Zealand's natural resource Deidre Kent, now concentrating on alcohol with tobacco control. conference on tobacco or health issues, was sorely missed, as was $\mathrm{Dr}$ Michael Carr-Gregg of the New Zealand Drug Foundation, Dr Robert Beaglehole and Sir David Hay of the Heart Foundation, and Jeannie Weir, Deidre's successor at ASH. Counteradvertising geniuses Judy Berry and John Roberts did not make it over from the United Kingdom; nor did smoking cessation researcher $\mathrm{Dr}$ Michael Russell. The absence of Norway's tobacco control leader Dr Kjell Bjartveit was a great disappointment. Travel funding cutbacks kept many talented US leaders from attending, including the National Cancer Institute's Don Shopland and Massachusetts Office for Nonsmoking and Health director Dr Greg Connolly. Also missed were Massachusetts Group Against Smoking Pollution (GASP) strategist Ed Sweda, Tobacco Product Liability Project founder Richard Daynard, Minnesota Association for Nonsmokers' president Jeanne Weigum, Stop Teenage Addiction to Tobacco's Joe Tye, Doctors Ought to Care's Dr Rick Richards, epidemiologist Dr Mike Cummings, researcher Dr Ernst Wynder, former Surgeon General C Everett Koop, and Dr David Burns, longtime senior scientific editor of the Surgeon General's reports.

Many unsung heroes did make it to Argentina, including Joe Capro of the Indiana Lung Association, who has attended every world conference on smoking (at his own expense); Dr Gus Miller, a pioneer in unpopular research conclusions such as the lack of benefit of low tar cigarettes; Cecilia Ferron, Bristol, England's leading activist; Judith Watt, director of the

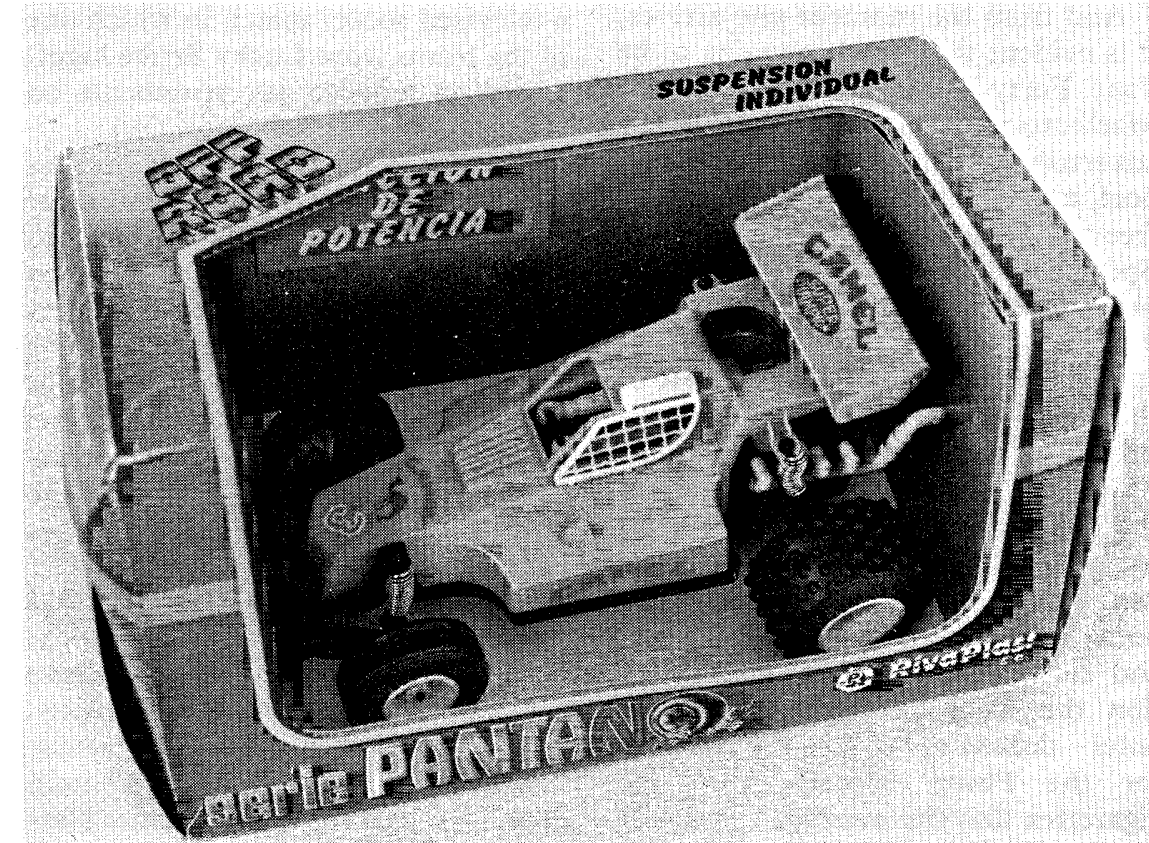

Camel toy car purchased in a gift shop at the Sheraton Hotel, which hosted the eighth world 
United Kingdom's No-Smoking Day, making a farewell visit before venturing into a new aspect of public service; Dr Lee Fairbanks, who led the successful campaign for smokefree hospitals in the US Indian Health Service; Dr Zdenek Kucera of Czechoslovakia, whose Columbus Project aims to send tobacco back to America; Dr Hans Adriaanse, one of the most productive researchers on the subject of health professionals and smoking behaviour; Dr Tom Houston, the American Medical Association's strategist on tobacco issues; Dr Derek Yach, a tireless force in tobacco control activities in South Africa; and Dr Murray Laugesen, an especially prickly thorn in the New Zealand tobacco industry's side. $-\mathrm{AB}$

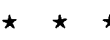

For some time [we] have been convinced that there is a causal relationship between the increased incidence of bronchogenic carci- noma and the increased use of cigarettes. There is a distinct parallelism between the sale of cigarettes and the incidence of bronchogenic carcinoma... Because the carcinogenic effect of cigarette smoking does not become evident until many years after smoking (approximately 20 ), it is frightening to speculate on the possible number of bronchogenic cancers that may develop as the result of the tremendous numbers of cigarettes consumed in the two decades from 1930 to $1950 \ldots$ With the predicted death rate from bronchogenic carcinoma of $29 \cdot 4$ per 100000 population in 1970 , it may be estimated that the annual deaths from this cause will increase from 16450 in 1948 to 47000 in $1970 \ldots$... Because of increased cigarette smoking it is likely and probable that bronchogenic carcinoma soon will become more frequent than any other cancer of the body, unless something is done to prevent its increase...

For nearly two years following this prediction by Drs Alton Ochsner, Paul DeCamp, Michael DeBakey, and CJ Ray in the 1 March 1952 issue of the fournal of the American Medical Association ( $f A M A$ ), the journal continued to accept cigarette advertising, for the authors' conclusions were by no means widely accepted by the medical profession. Yet if anything, Ochsner's prediction proved to be an underestimate: more than 60000 deaths from lung cancer occurred in 1970. Although others such as Doll and Hill in the United Kingdom and Wynder and Graham in the United States are credited with establishing smoking as an aetiological factor in cancer of the lung, Ochsner and DeBakey had published their observations about the origins of primary pulmonary malignancy as early as 1939 in the journal Surgery, Gynecology and Obstetrics (68: 435). And in April 1941, a little more than half a century before the eighth world conference on tobacco or health, Ochsner had presented a paper, "The effect of smoking on carcinoma of the lung," at the Asociación de Caballeros para la Lucha contra el Cáncer in Buenos Aires. $-\mathrm{AB}$

\section{Eighth world conference on tobacco or health}

Buenos Aires, Argentina, 30 March-3 April 1992

\section{Conference resolutions}

\section{International support}

(1) The conference participants congratulate the World Bank and the United Nations Children's Fund (UNICEF) on their support for tobacco control and urge them to persuade other international organisations to follow their example.

(2) The conference participants express their appreciation and continuing support to Honorary Chair, Dr Antonia Novello, for her leadership and continuing efforts, particularly to end tobacco advertising and promotion in order to protect the children of the world.

(3) The conference congratulates the Australian federal government on its decision to ban tobacco advertising and calls upon the governments of the United Kingdom, Germany, the Netherlands, and Greece to support the proposed European Commission directive to ban all tobacco advertising within the European Community. The conference instructs the chairman to write to the prime ministers of these four countries urging them to support the directive.

\section{International trade and promotion}

(1) The conference condemns those practices of the multinational tobacco industries that break down barriers designed to protect citizens of countries, particularly in the south, and calls upon all governments and international organisations to work toward tighter controls and restrictions on cross border marketing and promotion of tobacco.

(2) The conference applauds Taiwan's efforts to curb tobacco use and calls on the United States government to respect Taiwan's sovereign right to protect the health of its people through tobacco control legis- lation, and calls on the United States government to give priority to human health over tobacco profits in negotiating with Taiwan and other nations.

(3) The conference condemns the introduction of new tobacco products and promotions, particularly those designed to attract young people, and urges governments in collaboration with tobacco control organisations to ban products such as those made with flavoured or sweetened tobacco as well as promotions such as Joe Camel.

(4) The conference condemns the dumping of high tar and nicotine tobacco by European and North American tobacco industries into southern developing countries, and calls on all northern governments concerned to end these practices, and calls for a review of this effort by the ninth world conference.

\section{Support for international efforts}

(1) The conference participants applaud the planners for the increase in invited women speakers from less than $10 \%$ at the last world conference to over $30 \%$ at the eighth. The participants call on the organisers of future world conferences to make further progress by ensuring appropriate representation based on gender, race, and region. This will include action to substantially increase the numbers of women participants and plenary and scientific speakers; to increase bursaries for women; to provide child care facilities; and to consult the International Network of Women Against Tobacco (INWAT) in the planning, organising, and content of future world conferences.

Furthermore, resources should be increased for tobacco use prevention and cessation programmes for women, and financial contributions sought to further develop INWAT, and to provide funding and organi- sational support to assist women to work on the issue of women and tobacco, and to include issues of inequity and health due to gender, race, and region in future world conferences.

(2) The conference strongly urges the International Civil Aviation Organisation to adopt provisions prohibiting smoking on all commercial, passenger aircraft flights, domestic and international, and to collaborate with the World Health Organisation.

\section{Taxes}

(1) The conference urges governments to substantially increase taxes on tobacco products to reduce tobacco use, particularly among young people, while increasing government revenues for positive social services and support.

(2) The Conference participants urge that governments cease providing tax breaks and, therefore, incentives, for direct or indirect advertising of tobacco products, for promotion, or for expenses incurred in lobbying or public relations that enhance the sale or marketing of tobacco products; and call for a review of progress on this issue at the ninth world conference.

Promotion and advertising against tobacco

(1) By the ninth World Conference and in time for worldwide launching at that event, an international symbol should be created with accompanying global campaign messages to imprint tobacco control as a worldwide movement.

(2) Organisers of the Barcelona Olympics should be approached, through the World Health Organisation, to take on the symbolism and messages of a smoke-free 
Olympics by providing gold medals, particularly to the Olympic Committee; by providing symbols to the participating athletes; and by providing commentary to media covering the Olympics on the meaning of the symbols and the movement for tobacco control.

(3) Further efforts should be made to ensure that all subsequent Olympic events are smoke-free and that similar actions are undertaken.

(4) A large participation of educators and educational institutions in tobacco control worldwide at world conferences should be encouraged, beginning with the ninth world conference.

(5) The conference applauds the advanced tobacco control efforts in California, which provide new models for the international community, and calls upon the governor and the legislature to adhere to the original letter of the Proposition 99 law passed by the voters in 1988

(6) The organisers of the ninth world conference should request that the delegates bring examples of their education and information materials for a special exhibition, and for a one day workshop focusing on developing countries to be included in the program.

\section{Funding}

Between now and the ninth world conference an international committee should be formed to assess regional funding needs and to develop strategies for funding; these strategies and plans should be reviewed with a number of international donors; these donors should be invited to the ninth world conference to establish collaborative funding on a larger scale than in the past; and this funding should be for smoking control efforts and research, particularly in developing countries. The International Union Against Cancer (UICC) should be approached to coordinate this effort.

\section{Banking on health}

According to Tobacco Reporter correspondent David Doolittle (7/91), British-American Tobacco (BAT) depends on more than 500000 individual farmers for the bulk of its leaf tobacco. He notes that since tobacco takes up less than half of the crop growing season in Africa, tobacco is rotated with other crops, "which prevents disease and nutrient depletion. Production of food and additional cash crops, then, is not only undisturbed, but even enhanced. Points out BAT Kenya Chairman Dr Mareka Gecaga, 'Our experience is that, by introducing tobacco into the farmers' crop cycle, food production has increased up to three-fold." "

This view is not shared by the chief of the Population, Health and $\mathrm{Nu}$ trition Division of the World Bank, Dr Anthony $\mathrm{R}$ Measham. In a letter sent in January in reply to Dr SG Vaidya, secretary of the Goa Cancer Society in Goa, India, Dr Measham described the World Bank's newly approved policy on tobacco:

\section{The Bank will not lend directly for tobacco production, processing, imports, or marketing, whether for domestic consumption or for export. Indirect lending to identifiable tobacco projects will also be avoided to the extent practicable. \\ 2 The Bank's activities in the health sector-including sector research, policy dialogue, and lending opera- tions - will encourage a reduction in the use of tobacco products.}

The reason for our policies is that the costs to society of tobacco consumption are considerable. These costs include the resources used for medical treatment of persons with tobacco-related diseases and the value of the years of life lost due to morbidity and premature mortality arising from these diseases.

At the opening ceremonies of the eighth world conference on tobacco or health, Dr Hiroshi Nakajima, Director-General of the World Health Organisation, cited the new World Bank policy. The bank's represen- tative at the conference, José Luis Bobabilla, also mentioned the policy in his plenary presentation. The tireless Dr Vaidya, who was in the audience in Buenos Aires, visited with World Bank officials in Washington following the conference and reports that he was impressed by their commitment to the reduction of tobacco consumption. $-\mathrm{AB}$

\section{Australia's new health warnings on cigarette packaging}

On 15 April 1992 the Australian Ministerial Council on Drug Strategy (MCDS), at a joint meeting of State and Federal Health Ministers, agreed that all states would regulate to modify health warnings on tobacco packaging in line with recommendations made to it based on research conducted by the Centre for Behavioural Research in Cancer (CBRC). In essence this will mean that cigarette packs will have one of 12 rotating health warnings at the top of the front covering a minimum of $25 \%$ of the surface; one side taken over for detail of tar, nicotine, and carbon monoxide contents; and the entire back taken over by elaboration of the front side warning, a listing of major risks of smoking, and a "Quitline" number to ring for further information or help with quitting. The accompanying picture indicates what the new regulations mean for the appearance of Australian cigarette packs. Further detail about the recommendations is provided below. MCDS also agreed to consider a further set of CBRC recommendations about requiring standardised packaging of cigarette packets. These recommendations would require legislation and will be considered in a year's time.
The rationale for the recommendations was based on an acceptance that health warnings by themselves would be likely to have little effect on confirmed smokers, but would be most likely to affect those in the process of taking up smoking (mainly young people) and those contemplating quitting. The former group (children) are a priority for drug control strategies in Australia.

To be effective health warnings need to be noticed, to be persuasive, and to provide guidance for appropriate action. To be noticed, health warnings need to stand out from the surrounding pack design and they need to be large enough to be read easily. To be persuasive, the warnings need to be understood, believed, and judged to be personally relevant by the reader. It follows that warnings about a range of ill effects of smoking which are comprehensive increase the chance that people reading them will find at least one ill effect with which they relate. Finally, the effectiveness of any call to action is enhanced by specific instructions about the first step to take.

The general recommendations made by CBRC which were accepted by the MCDS and some of the detail of supporting recommendations is provided below.

\section{Effective labelling about the contents of tobacco smoke}

The dangerous contents of tobacco smoke should be effectively conveyed on the packaging of all tobacco products.

Specific recommendations include:

- That an entire side of the pack be given over to this information

- That tar, nicotine, and carbon monoxide levels be accurately specified - that is, within $1 \mathrm{mg}$ of tested levels of tar and carbon monoxide and $0.1 \mathrm{mg}$ of tested levels of nicotine

- That a brief explanation of what each of these constituents is and does 

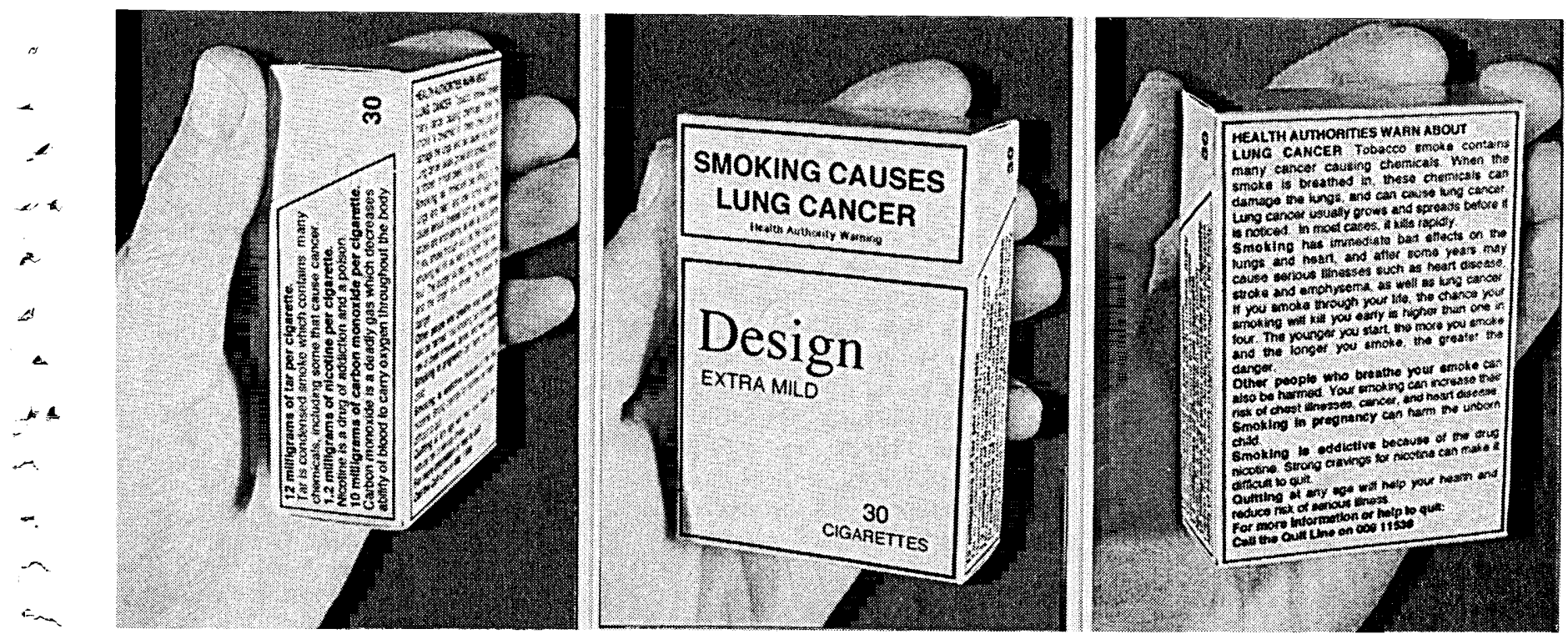

Prototype of a cigarette packet with warning labels recommended by the Centre for Behavioural Research in Cancer, Anti Cancer Council of Victoria, Australia

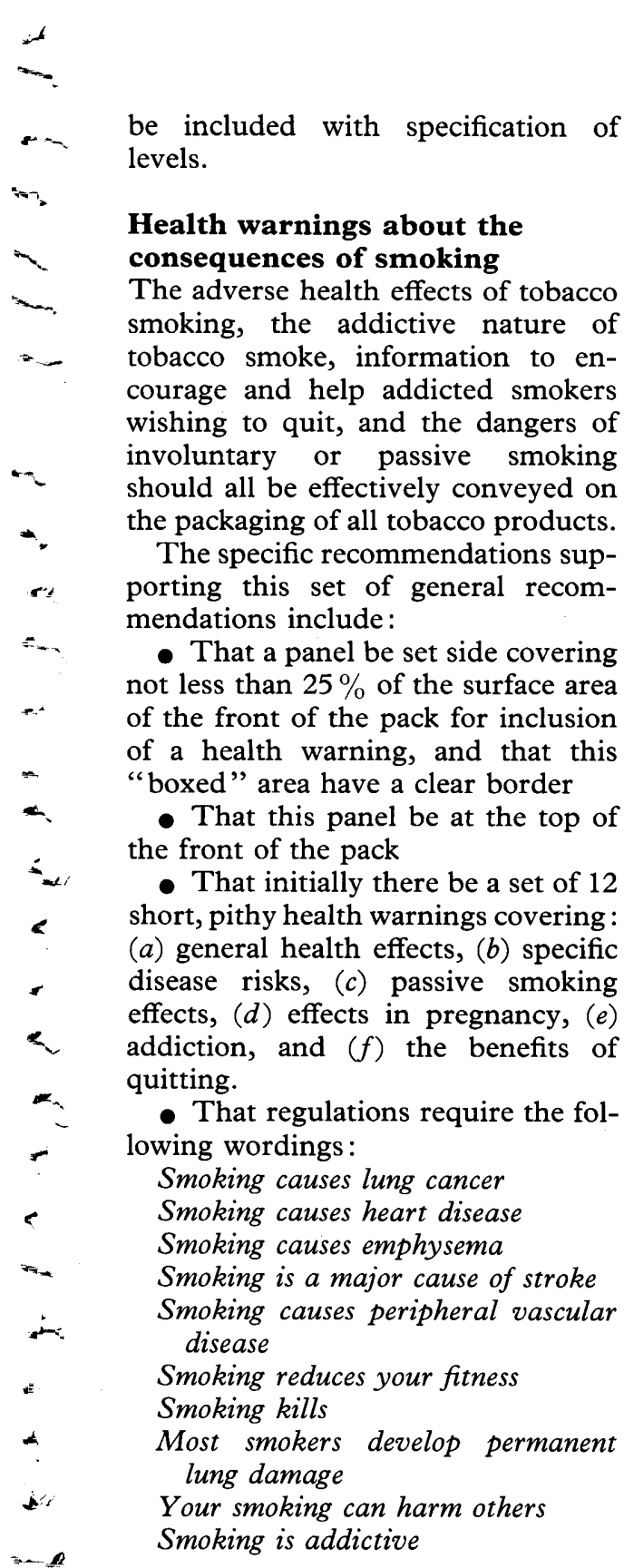

Stopping smoking reduces your risk of serious disease

Smoking in pregnancy can harm the unborn child

- That the back of the pack be given over entirely to the provision of more detailed health information

Health authorities warn smoking can kill you

LUNG CANCER. Tobacco smoke contains many cancer-causing chemicals. When the smoke is breathed in, these chemicals can damage the lungs, and can cause cancer. Lung cancer is the most common cancer caused by smoking. Lung cancer usually grows and spreads before it is noticed. In most cases, it kills rapidly.

Smoking has immediate bad effects on the lungs and heart, and after some years may cause serious illnesses such as heart disease, stroke, and emphysema, as well as lung cancer. If you smoke through your life, the chance your smoking will kill you early is higher than one in four. The younger you start, the more you smoke and the longer you smoke, the greater the danger.

Other people who breathe your smoke can also be harmed. Your smoking can increase their risk of chest illnesses, cancer, and heart disease.

Smoking in pregnancy can harm the unborn child.

Smoking is addictive because of the drug nicotine.

Strong cravings for nicotine can make it difficult to quit.

Quitting at any age will help your health and reduce risk of serious illness.

For more information or help to quit: Call the Quitline on 00811538. about the harmful consequences of smoking

- That the panel on the back of the pack contain standard information on the following seven areas: (a) elaboration of front side warning (for instance, a paragraph explaining more about the nature of lung cancer and its relation to smoking), (b) overall health risks, (c) passive exposure risks, $(d)$ dangers of smoking in pregnancy, $(e)$ addictive nature of tobacco, $(f)$ benefits of quitting, and $(g)$ where to get help in quitting.

Plans have been developed to establish a national telephone network Quitline, the number for which will be included on the pack.

The box provides an example of a complete back of pack text. The first paragraph is specific to lung cancer and would match up to the front of pack warning, Smoking causes lung cancer. This text would occupy the entire reverse side of a standard pack of cigarettes.

\section{Implementation}

All these recommendations are scheduled to come into force on 1 July 1993. Before that all states and territories will need to regulate in a uniform way as tobacco health warnings are subject to state legislation in Australia. The agreement of MCDS should ensure that this occurs, as it was agreed that only implementation, not the content of the recommendations, be the subject of discussions with the tobacco industry.

When implemented, Australia will have the strongest and most informative warning system for tobacco in the 
world. The use of the back of the pack to elaborate health risks, explanation of the dangers of the major harmful contents, and the provision of a Quitline number are all innovations.

The research conducted by Centre for Behavioural Research in Cancer both demonstrated the need for more effective labelling and provided some evidence that this package of measures is likely to act as a deterrent to young people taking up smoking and may assist intending quitters. Its impact will be enhanced if it is accompanied by strong and consistent policies directed at discouraging tobacco use. Australia has a good track record in this regard, so we might expect further declines in the prevalence of smoking in Australia as a result of this and other measures.

DAVID HILL Anti Cancer Council of Victoria, Victoria, Australia

The full report is available from the Centre for Behavioural Research in Cancer, 1 Rathdowne Street, Carlton South, Victoria 3053, Australia, price $\$$ A30.

\section{New director for US Office on Smoking and Health}

The new director of the US Centers for Disease Control's Office on Smoking and Health (which was recently transferred from Rockville, Maryland, to Atlanta, Georgia) is Michael P Eriksen, ScD, formerly of the MD Anderson Cancer Center in Houston, Texas. Dr Eriksen is regarded as a soft spoken and effective coordinator of prevention programmes. Reviewing the 15th international cancer congress in Hamburg in 1990 for the Cancer Bulletin (12/90) of the MD Anderson Cancer Center, Dr Eriksen was clearly shaken by the presentation of British epidemiologist Richard Peto, who pre- dicts a worldwide toll of 10 million deaths a year caused by tobacco by 2025. Alluding to the unethical disregard the United States shows towards the future health of developing nations as evidenced by its trade policies and the marketing tactics of its tobacco industry, Eriksen writes, "Although many of us are personally active in tobacco control efforts [in the United States], at international meetings we are often confronted about our federal policies that will certainly, as shown by Peto's projections, result in unequalled death and suffering in those countries least able to cope with the medical and social consequences of tobacco use."

$$
-A B
$$

\section{Virtual greed?}

Analysts at Shearson Lehman and Morgan Stanley repeated their "buy" recommendations on RJR Nabisco, based on a weakening in the price of the stock after the United States Surgeon General requested the company stop using the "Joe Camel" cartoon character in cigarette advertising.

Stock trading report, New York Times, 11 March 1992

The term "virtual reality" has been coined to describe the next wave of computer simulated video games that create for the player a three dimensional illusion of being in the game itself. After reading the New York Times' report of March 11 on the previous day's trading on the New York Stock Exchange, I was moved to coin a new term: virtual greed. $-A B$

\section{Essential resources}

Tobacco Reporter, published monthly by Specialized Agricultural Publications Inc, PO Box 95075, Raleigh, NC 27690-2503, USA. Aggressive, illustrated international publication for the tobacco industry; a year's subscription is $\$ 65$.

Smoking: Death, Disease, and Dollars. Massachusetts Department of Public Health, 150 Tremont Street, Boston, MA 02111,
USA. November 1991. Not your usual health department document: gets to the heart of smoking-attributable costs.

Smoking Prevention : An A-Z of Useful Ideas. HEA Smoking Prevention Field Support Project, Bristol Polytechnic, Redland Hill, Bristol BSG 6UZ, United Kingdom. $£ 1.50$ September 1991. Written by Kate Woodhouse, designed by Sarah Siddall, produced by Cecilia Farren and Judith Watt - geniuses all. A hilarious jam packed pot-pourri of good clean fun and good dirty tricks. One of a series. See $\mathrm{p} 142$.

From the Billboard to the Playground. A resume of the academic research on the influence of advertising on children's smoking, by GB Hastings, PP Aitken, AM Mackintosh, Cancer Research Campaign, 2 Carlton House Terrace, London SW1Y 5AR, United Kingdom. A neat rebuttal to industry claims that the market for tobacco products is "mature."

GLOBALink, 1730 Rhode Island Avenue, NW, Suite 600, Washington, DC, 20036, USA. This electronic communications network established by the American Cancer Society and the Advocacy Institute reprints mass media stories on tobacco issues and provides an opportunity for health advocates to share views.

Tobacco Action Pack, a resource of the International Organisation of Consumers Unions' AGHAST (Action Groups to Halt Advertising and Sponsorship by Tobacco), PO Box 1045, 10830 Penang, Malaysia; edited by Marina Emmanuel. - AB

Tobacco on Trial : Reporting on Litigation and Other Tobacco Control Strategies. Published 10 times a year. Subscriptions $\$ 95$ standard, $\$ 65$ for public and academic libraries, $\$ 35$ for smoking control activists and organisations and for the news media. Payment to Tobacco on Trial, Northeastern University School of Law, 400 Huntington Avenue, Boston, MA 02115, USA.
Ideas and items for News Analysis should be sent to Alan Blum, editor for news and commentary, at the address given on the inside front cover, or to Eric I Solberg, assistant news editor, at the same address. 